\title{
FOREIGN BODY IN CRICOPHARYNX: AN UNUSUAL PRESENTATION
}

\section{Shaila Sidam ${ }^{1}$}

\section{HOW TO CITE THIS ARTICLE:}

Shaila Sidam. "Foreign Body in Cricopharynx: An Unusual Presentation". Journal of Evolution of Medical and Dental Sciences 2015; Vol. 4, Issue 72, September 07; Page: 12603-12604, DOI: 10.14260/jemds/2015/1814

ABSTRACT: A foreign body in the cricopharynx causes severe discomfort to the patient and is a potential threat to the airway. Here we present a unique case report of a 3 month old male infant with accidental insertion of foreign body (Locket) in the cricopharynx.

KEYWORDS: Cricopharynx, Foreign body, Locket.

INTRODUCTION: Out of all the emergencies reporting in ENT Department, foreign body impacted in upper GI tract is most alarming and apprehensive. A common problem in adults and children, though the incidence is more in children than adults. Less than $1 \%$ of foreign bodies result in serious morbidity. ${ }^{1}$

Foreign bodies tend to lodge in sites of constriction in the oesophagus. A foreign body in the cricopharynx causes severe discomfort to the patient and is a potential threat to the airway. Its removal should be carried out as soon as possible since the pooled saliva can obstruct the airway. ${ }^{2}$

The most common sites of impaction are cricopharynx (70\%), aortic arch indentation (20\%) and rarely at gastro-oesophageal junction (10\%).

Various types of foreign bodies are impacted in G.I. tract. Most of them are usually coins, bones (Fish, chicken) less common are buttons, chocolate, toffees, meat bolus, battery cells, artificial dentures.

CASE REPORT: A 3 month old male infant presented to ENT emergency of GRMC, Gwalior with the complaints of accidental insertion of foreign body (locket) since few hours. He had complaints of dysphagia and 2 to 3 episodes of vomiting but no respiratory distress. X-ray soft tissue neck and upper chest AP view revealed a metallic foreign body of $2 \mathrm{~cm}$ in diameter at the cricopharyngeal level.

Rigid oesophagoscopy was performed and superiorly a horizontally impacted metallic foreign body in cricopharynx was seen, conventional foreign body catcher was used and foreign body was disloged and then removed vertically to avoid any perforation. The child was asymptomatic and discharged from the hospital the next day.

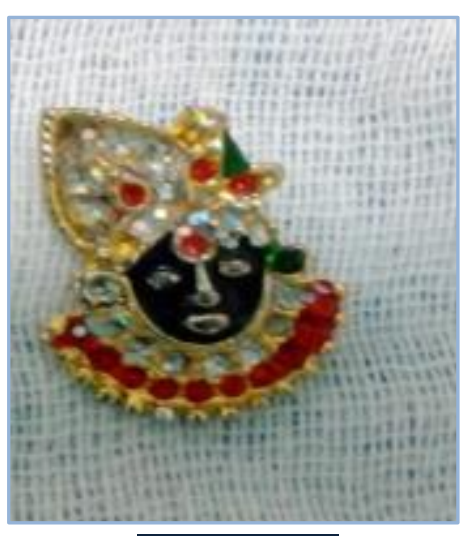

Fig. 1

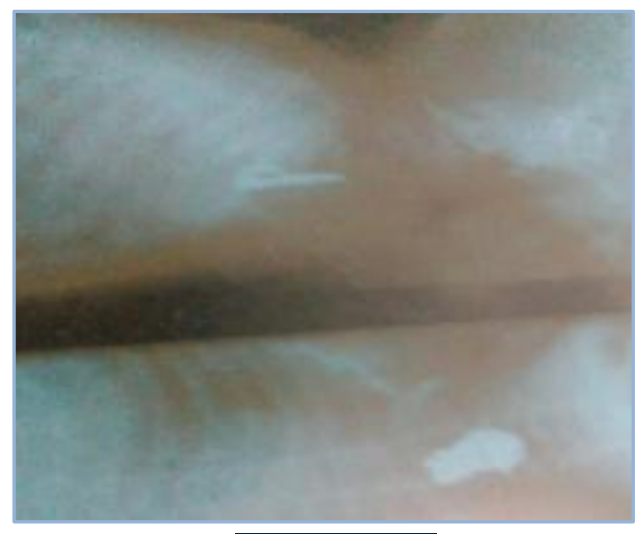

Fig. 2 
DISCUSSION: Foreign body ingestions or insertions is more common in children than in the adults and is usually seen in the following categories of patients:

A. Mentally handicapped or mentally retarded persons.

B. Accidental ingestion.

Typical examples include children swallowing coins and mentally handicapped adults swallowing metallic or sharp objects. Fortunately, the vast majority of all swallowed objects pass through the gastrointestinal tract without a problem. Mostly they are lodged at the constrictions.

Most upper GI foreign bodies are related to food impaction, because of not proper mastication or swallowing, with meat (Bone) most often being lodged. If the Foreign Body lodges in the cricopharyngeal sphincter or esophagus, early removal under general anesthesia is performed.

Patients treated in this manner has no morbidity and a short hospital stay.3,4 Our case was unique as it occurred in a three month old infant with the foreign body impacted in cricopharynx horizontally which was disimpacted and removed.

\section{REFERENCES:}

1. Kumar A, Singh S, Low C, Shahab R: A safe and cost-effective method of removal of obstructed pharyngeal foreign body in the accident and emergency department. Eur Arch Otorhinolaryngol 262: 192-193, 2005.

2. Cangir AK, Tug T, Okten I: An unusual foreign body in the esophagus: report of a case. Surg Today 32: 523-524, 2002.

3. Selivanov V, Sheldon GF, Cello JP, Crass RA: Management of foreign body ingestion. Ann Surg 199 (2): 187-191, 1984.

4. Yip LW, Goh FS, Sim RS: I've got a UFO stuck in my throat--an interesting case of foreign body impaction in the oesophagus. Singapore Med J 39(3): 121-3, 1998.

\section{AUTHORS:}

1. Shaila Sidam

\section{PARTICULARS OF CONTRIBUTORS:}

1. Assistant Professor, Department of ENT, Gajra Raja Medical College, Gwalior.

FINANCIAL OR OTHER COMPETING INTERESTS: None
NAME ADDRESS EMAIL ID OF THE CORRESPONDING AUTHOR:

Dr. Shaila Sidam, Room No. 36, Senior Girls Hostel, Gajra Raja Medical College, Gwalior.

E-mail: gujulsidam@yahoo.co.in

Date of Submission: 20/08/2015. Date of Peer Review: 22/08/2015. Date of Acceptance: 02/09/2015. Date of Publishing: 07/09/2015. 